\title{
LA MUCHACHA ENAMORADA EN LA COMEDIA LATINA ${ }^{1}$
}

\author{
Antonio Arbea \\ aarbea@uc.cl \\ Facultad de Letras, Pontificia Universidad Católica de Chile
}

\section{RESUMEN / ABSTRACT}

El propósito de este trabajo es caracterizar e interpretar la evolución del personaje de la muchacha enamorada en la comedia latina. Específicamente, se consideran aquí los dos momentos más salientes del género: de un lado, la antigua comedia romana de Plauto y Terencio, y, del otro, la así llamada comedia humanística latina, escrita en el temprano Renacimiento europeo. De entre estas últimas piezas, me interesará específicamente examinar los casos de Symmachus y Emporia, dos comedias de Tito Livio Frulovisi que hasta hoy no han sido traducidas a ninguna lengua moderna.

Palabras clave: Tito Livio Frulovisi, comedia humanística latina, Renacimiento, "Symmachus", "Emporia".

The purpose of this work is to characterize and interpret the development of the character of the young girl in love in the Latin comedy. In consequence, the research focuses on the genre's two most prominent periods: the ancient Roman comedy by Plautus and Terence, and the so-called Latin humanistic comedy from the early European Renaissance. More specifically, this work concentrates on the cases of Symmachus and Emporia, two comedies by Tito Livio Frulovisi which have not been translated to any modern language.

KEY WORDS: Tito Livio Frulovisi, humanistic Latin comedy, Renaissance, "Symmachus”, "Emporia".

1 Este artículo es resultado del proyecto Fondecyt Regular n. ${ }^{\circ} 1120388$, titulado "Symmachus, de Tito Livio Frulovisi (comedia humanística latina). Introducción, texto, traducción, notas e índice de palabras", en el que participaron Antonio Arbea (investigador responsable) y Javier Beltrán (ayudante). 


\section{INTRODUCCIÓN}

Este trabajo -realizado en el marco de un proyecto mayor, destinado a editar y traducir la comedia humanística latina Symmachus, de Tito Livio Frulovisifue sugerido por sendas observaciones de dos estudiosos de la literatura latina del Renacimiento, María Rosa Lida y Antonio Stäuble. Según la investigadora argentina, "uno de los rasgos distintivos de la comedia humanística es su original galería de jóvenes enamoradas, resultado de su entronque con la narración sentimental de la Edad Media" (455). Stäuble, por su parte, señala que los autores de las comedias humanísticas latinas, apartándose de los esquemas de Plauto y Terencio,

han dado vida a figuras femeninas más vecinas a aquellas que animan muchas novelas de la época. Las mujeres, incluso las casadas, llegan a ser protagonistas de acontecimientos de los cuales a menudo determinan directamente el curso [...]. Son figuras dotadas de voluntad y personalidad propias y que constituyen verdaderamente un personaje (traducción mía) (180-181)².

El objetivo de este trabajo es caracterizar el personaje de la muchacha enamorada en los dos momentos de mayor relieve -a mi juicio- de la comedia latina: por un lado, la antigua comedia romana de Plauto y Terencio, y, por otro, la comedia latina del temprano Renacimiento -en particular, las comedias Symmachus y Emporia, de Tito Livio Frulovisi-. Procuraré, además, relacionar los rasgos del personaje con las circunstancias históricas de su creación. Adicionalmente, ofrezco aquí la primera traducción a una lengua moderna de un par de pasajes de las mencionadas comedias de Frulovisi.

Quiero señalar, además, que durante la elaboración de este trabajo he tenido en mente con frecuencia La Celestina y, especialmente, como es natural, la figura de Melibea. En ningún momento, sin embargo, he querido proponer eventuales conexiones entre la Tragicomedia y las piezas de Frulovisi aquí examinadas. Por ahora, me he limitado a examinar uno solo de los miembros de la pareja -la comedia latina antigua y la humanística-,

\footnotetext{
"[...] hanno dato vita a figure femminili piu vicine a quelle che animano molte novelle dell'epoca. Le donne, anche sposate, diventano protagoniste di vicende di cui spesso esse determinano addiritura il corso [...]. [Sono] figure dotate di volontà e personalità propria e che costituiscono veramente un personaggio".
} 
mostrando especialmente aquellos rasgos que pueden ser operatorios para una confrontación posterior. Todavía, en efecto, quedan cosas por hacer en lo relativo a precisar la condición de fuentes de La Celestina que tienen "esas comedias latinas compuestas por los eruditos italianos del siglo decimoquinto" (vol. $3^{\circ}, 240$ ), como apuntaba hace ya más de cien años Menéndez Pelayo. Y es oportuno recordar aquí que es muy probable que Fernando de Rojas haya tenido conocimiento directo de una de "esas comedias latinas": la Philogenia, de Ugolino Pisani, escrita por los mismos años que Symmachus y Emporia. En efecto, como lo señaló María Rosa Lida $(1956,423)$, un ejemplar de la Margarita Poetica -antología hecha por el humanista alemán Albrecht von Eyb y publicada por primera vez en Núremberg en 1472, que trae la comedia de Pisani traducida al alemán- figura en el inventario de los libros legados por Fernando de Rojas a su mujer (Valle Lersundi 382).

\section{LA COMEDIA ROMANA ANTIGUA}

Las comedias de Plauto y Terencio ${ }^{3}$ ofrecen, en la mayoría de los casos, un mismo argumento base: un joven (adulescens) está perdidamente enamorado de una cortesana (meretrix), pero no tiene dinero para comprar los servicios de la muchacha, que es administrada por su dueño, un avaricioso lenón (leno). El joven recibe entonces la ayuda de un esclavo de su familia (servus fallax), quien, haciendo gala de su astucia, le consigue el dinero burlando ya sea al propio lenón, ya sea al padre del joven (durus pater).

Lo primero que corresponde señalar es un hecho que, en principio, puede sorprender: que en Plauto y Terencio jamás uno se encuentra con el arrebato impetuoso de jóvenes enamoradas. La costumbre antigua no permitía que una doncella enamorada apareciera en escena expresando su intimidad. Esa moral no impedía, es cierto, que se representaran escenas vivas de amor, pero a condición de que se tratara de una prostituta. Una muchacha libre no era considerada como objeto del mismo amor que una cortesana; cuando ella se casaba, era tratada con respeto, pero no con pasión. En esa Roma, como sabemos, el matrimonio no estaba fundado en el amor, no era la consagración legal de la atracción de dos personas, sino una alianza de otra especie. En esa alianza podía surgir el amor, por cierto, pero ello no era necesario, ni 
siquiera deseado, pues se estimaba que el matrimonio -contrato importante personal y socialmente- debía reposar sobre sentimientos menos frágiles. Ya entonces, pues, se tenía claro aquello de que las promesas de amor no obligan. Las heroínas de la comedia romana, en consecuencia, son, sistemáticamente, esclavas o cortesanas que protagonizan un amor ilegítimo, separado del matrimonio, y su participación directa en la acción dramática es muy escasa.

En el caso de Plauto, casi todas las muchachas en torno a las cuales se desenvuelve la intriga amorosa coinciden en tener un muy bajo relieve, a pesar de que ellas constituyen, regularmente, el motor de la acción dramática. El caso de la comedia Casina, por ejemplo, es notable. Allí toda la trama gira alrededor de los esfuerzos del joven Eutinico y de su padre Lisídamo - enzarzados en una poco edificante rivalidad amorosa- por llegar a poseer a la esclava Cásina. Y lo más sorprendente de todo -o lo más revelador- es que ella no pisa jamás la escena, no dice una sola palabra en toda la obra. Lo que Cásina piensa o siente, simplemente no importa.

Cuando, a diferencia de lo que ocurre en Casina, estas muchachas - cortesanas o esclavas- abren la boca para manifestar su amor, lo hacen para expresar un convencional y pálido sentimiento, si no meramente el deseo de que se les paguen bien sus servicios. Así, apenas puede hablarse de amor en las relaciones pasajeras que Plauto nos ofrece de esos muchachos con las jóvenes a las que pretenden. Más que amor, en el sentido en que lo entendemos hoy día, lo que hay es amorío, aventura, amor sensual y elemental, sin introspección ni sentimentalismo, y siempre desde la perspectiva del joven, no de la muchacha.

Hay que reconocer, sin embargo, que medio siglo más tarde, en el teatro de Terencio, la situación es en parte distinta. Algo ha cambiado en las costumbres. La meretriz de las comedias de Terencio ya no es considerada simplemente como instrumento de placer, como objeto de un súbito y perentorio antojo pasional, propio de la juventud. Ella asoma aquí ya como una compañera por la cual el joven puede experimentar una sincera ternura y que, por su parte, puede corresponder con genuino amor. En Terencio, el lector percibe que las relaciones amorosas se han liberado parcialmente de su rudeza primitiva y tienden a espiritualizarse. Eso es lo que se aprecia, por ejemplo, en ese verdadero drama familiar que es Hecyra (La suegra), donde la cortesana Baquis, dando muestras de delicados sentimientos, supera sus propios celos y se preocupa de proteger el bienestar conyugal de su amante. El matrimonio mismo, además, ya no es visto como un castigo, sino como la recompensa del amor. 
Pero, sumando y restando, habría que decir que en la antigua comedia romana la heroína tiene regularmente un papel reducido y deslavado, nunca determinante en la acción. De ella se habla, pero se ignoran sus sentimientos y se desconoce su personalidad. Esta menoscabada participación hace recordar aquella sentencia griega del Áyax de Sófocles, según la cual "a las mujeres el silencio las adorna" (verso 293) ${ }^{4}$.

Sabemos que los antiguos romanos fueron tradicionalmente sexistas. Siempre respetaron el matrimonio y el hogar como instituciones, pero fue un respeto sin simpatía, sin afecto. No faltan testimonios de que casarse era para ellos un mal necesario que había que aceptar por el bien de la República. Metelo Numídico, censor el año 102 a. C., dirigiéndose a sus conciudadanos célibes, los exhorta con las siguientes palabras a que, por el bien de Roma, contraigan nupcias:

Si pudiéramos vivir sin esposa, conciudadanos, todos estaríamos libres de esa molestia; pero ya que la naturaleza ha establecido que no se puede vivir ni muy a gusto con ellas, ni de modo alguno sin ellas, es preciso velar por el bien permanente de la República [y casarse], antes que por nuestro breve placer [permaneciendo solteros] (trad. mía) (Gellius I, 6, 2) .

Pero, como nos relata Aulo Gelio, lo más revelador ocurrió a continuación: luego que Metelo dijo estas palabras, la discusión que se produjo entre algunos notables que estaban allí presentes no fue acerca de si el censor tenía o no razón en estimar que las esposas eran una molestia -eso, al parecer, estaba fuera de discusión-, sino acerca de si él había hecho bien o no en reconocer este hecho precisamente ante quienes estaba tratando de convencer de que contrajeran matrimonio.

Poco afecto, pues, se les tenía a las mujeres; poca consideración. Estos sentimientos se reflejan también en el antiguo derecho romano, donde se aprecia una concepción de la familia propia de una sociedad patriarcal arcaica. El derecho romano, en efecto, consagraba la total dependencia de la mujer, que siempre aparecía tratada como un ser inferior y privada de la mayoría de

\footnotetext{
"Gynaixí kósmon he sigé férei”.

"Si sine uxore vivere possemus, Quirites, omnes ea molestia careremus; sed quoniam ita natura tradidit, ut nec cum illis satis commode, nec sine illis ullo modo vivi possit, saluti perpetuae potius quam brevi voluptati consulendum est".
} 
los derechos de un hombre libre. Ella permanecía siempre como menor de edad, sometida primero a la tutela de su padre, más tarde a la de su marido $\mathrm{y}$, por último, en caso de enviudar, nuevamente a la de su padre, o a la de sus hermanos si el padre había muerto. El esposo tenía sobre ella, al menos en teoría, prácticamente todos los derechos, incluido el derecho de vida y de muerte, el ius vitae necisque, como si ella fuera una esclava.

La idea de que la mujer era un ser inferior se fundaba en la concepción -de raigambre griega- de que ella no se rige por el logos, sino por el instinto. Para Aristóteles, la mujer es un ser humano inferior: "[...] el macho es por naturaleza superior a la hembra; el uno gobierna, la otra es la gobernada. Este mismo principio se aplica también necesariamente a todos los seres humanos" (trad. mía) (Política 1, 1254 b 13-15) 6 . Las principales carencias femeninas eran tres: fuerza, inteligencia y constancia. Respecto a su inconstancia, Virgilio, acuñando una expresión que devendría proverbial, dirá más tarde que "la mujer es siempre algo variable y cambiante" (Eneida 4, 569)7.

Es curioso que, siendo la ley matrimonial de entonces tan favorable para el hombre, tan cuidadosa en velar por las prerrogativas masculinas, haya existido -desde tan antiguo como fines del siglo $\mathrm{V}$ a. C., al menos- la necesidad de exhortar con tanto empeño a los hombres a casarse. Sabemos, en efecto, que el año 403 a. C., por iniciativa de los censores Camilo y Postumio, se les impuso un tributo especial a los hombres que llegaban a cierta edad sin haber contraído nupcias (cf. Valerio Máximo II, 9, 1). No puede uno sino concluir que, ya desde esa época, los romanos, por la razón que sea, le tenían aversión al matrimonio. Este sentimiento se prolongó durante mucho tiempo, tanto así que el propio Octaviano Augusto, casi cuatro siglos más tarde -el 27 a. C.-, tuvo la idea de instituir la obligación de casarse. Posteriormente, sí, debió renunciar a imponer esta exigencia, tan ajena a la tradición jurídica romana, y en su lugar ideó un sistema de incentivos económicos para los hombres que fundaran un hogar legítimo, especialmente para los que en esos matrimonios tuvieran al menos tres hijos. (Con esta norma, que se la conoce como el ius trium liberorum, Augusto no pretendía aumentar la natalidad-los ciudadanos que podían interesarse por los beneficios de esta legislación formaban una

“[...] tò árrēn pròs tò thēly phýsei tò mèn kreîtton, tò dè kheīron, kaì tò mèn árkhon, tò d' arkhómenon. Tòn autòn dè trópon avagkaīon eīnai kaì epì pántōn anthrốpōn". Sobre este asunto de la inferioridad de la mujer en Aristóteles, cf. Femenías, passim.

"Varium et mutabile semper femina". 
minoría-, sino darle vigor y consistencia a la clase social de los dirigentes políticos, fundamentales para la suerte del Imperio).

Un siglo y medio después de Augusto, la Sátira VI de Juvenal (60-140 d. C.) testimonia todavía la tradicional repulsa masculina al matrimonio. La pieza está dirigida a un tal Póstumo, que está a punto de contraer matrimonio. El propósito de Póstumo le parece a Juvenal una verdadera locura. El poeta le sugiere que escoja otras formas mejores de suicidarse:

En verdad, tú solías ser cuerdo. ¿Te vas a casar, Póstumo? Dime por qué Furia eres perseguido, por qué serpientes ${ }^{8}$. ¿Puedes soportar tener un ama, cuando hay tantas sogas a tu disposición, cuando se hallan abiertas altas y sombrías ventanas, cuando vecino a ti se te ofrece el puente Emilio? (trad. mía) (versos 28-32) .

Para Juvenal, lo que especialmente vuelve insoportables a las mujeres es el dinero: "Nada hay más intolerable que una mujer adinerada" (verso 460) ${ }^{10}$. Detrás de lo cual, como es claro, lo que se esconde es el temor a que la mujer tenga poder, como ya Catón lo reconocía en un discurso pronunciado hacia el año 195 a. C. y dirigido a los varones:

Examinad las leyes sobre asuntos femeninos con las que nuestros mayores procuraron restringir la libertad de las mujeres y someterlas a sus maridos: incluso estando coartadas por tales normas, vosotros apenas sois capaces de dominar a vuestras esposas. ¿Qué pasará si les permitís desbaratar esas leyes una a una, si las dejáis conseguir sus propósitos valiéndose de la fuerza, si en fin toleráis que se igualen a sus esposos? ¿Pensáis que podréis soportarlas? Tan pronto como se igualen a vosotros, serán superiores a vosotros (trad. mía) (en Tito Livio 34,3$)^{11}$.

8 A las Furias se las representaba con serpientes entrelazadas a sus cabellos.

$9 \quad$ "Certe sanus eras. Vxorem, Postume, ducis?

Dic qua Tisiphone, quibus exagitere colubris.

Ferre potes dominam salvis tot restibus ullam, cum pateant altae caligantesque fenestrae, cum tibi vicinum se praebeat Aemilius pons?"

10 "Intolerabilius nihil est quam femina dives".

11 "Recensete omnia muliebria iura quibus licentiam earum alligaverint maiores nostri, per quaeque subiecerint viris: quibus omnibus constrictas vix tamen continere potestis. Quid 
La menguada presencia de la heroína en la comedia romana antigua, en suma, es una manifestación más de ese acendrado antifeminismo que encontramos en gran parte de la literatura latina, republicana o imperial, y puede verse como un síntoma de la desmedrada situación de la mujer en la antigua Roma ${ }^{12}$.

\section{LA COMEDIA HUMANÍSTICA}

La así llamada comedia humanística latina, fruto del temprano Renacimiento europeo -del período llamado precisamente Humanismo--, es la primera manifestación del teatro profano moderno.

En ausencia de modelos estructurales claros -ya que el teatro de la Edad Media se reducía prácticamente a los milagros, los misterios, los autosacramentales y las farsas, además de las improvisaciones de los juglares y de los mimos-, la comedia humanística consiguió dar un gran paso adelante. Su originalidad consistió en haber sido una consciente aproximación a las formas del teatro latino clásico, pero con personajes y temas nuevos. Fue el primer intento coherente de dramatizar asuntos contemporáneos, muchos de los cuales la tradición narrativa había hecho ya contenido de sus obras. La importancia histórica de la comedia humanística latina, más allá de su mediano mérito literario, está en ser el momento que conecta el teatro latino antiguo con el europeo renacentista y posterior.

Las comedias humanísticas latinas llegadas hasta nosotros son aproximadamente cincuenta, casi todas escritas durante el siglo XV italiano. El tema de la mayoría de ellas es el amor, pero entendido como amorío y presentado con los rasgos que ofrece en la comedia romana y en buena parte de la narrativa medieval: ansioso, básicamente sensual, físico, urgente, apartado todavía -en general- de las exaltaciones sentimentales del amor cortés. Pero, a diferencia de lo que ocurre en la comedia antigua, donde, más que el amor

si carpere singula et extorquere, et exaequari ad extremum viris patiemini? Tolerabiles vobis eas fore creditis? Extemplo, simul pares esse coeperint, superiores erunt”.

12 Entre la abundante bibliografía de que disponemos sobre este asunto, me permito recomendar especialmente el trabajo de Gunhild Vidén Women in Roman Literature, que investiga con perspicacia las actitudes hacia la mujer en las obras de Tácito, Suetonio, Plinio el Joven, Séneca, Juvenal y Marcial. 
mismo, lo que importa es el ardid ingenioso para lograrlo, lo que aquí interesa es efectivamente el episodio amoroso, sobre todo el episodio de la conquista.

En cuanto a los personajes de estas comedias, junto a algunos de origen plautino o terenciano -como el joven enamorado (adulescens amans) y el esclavo astuto (servus callidus), por ejemplo-, encontramos otros provenientes de la tradición narrativa medieval. Es el caso de los clérigos frívolos o corrompidos, los esposos burlados, los campesinos víctimas de su simplicidad y de la astucia de los hombres de ciudad, las mujeres que se lamentan de sus desdichas conyugales y que intentan remediarlas con amores extramaritales. $\mathrm{Y}$ en medio de estos personajes de nuevo cuño, asoma con fuerza la figura de la muchacha que expresa abiertamente sus sentimientos amorosos, motivo que poco o nada le debe a la comedia romana, donde la heroína, como hemos visto, nunca es figura dominante. En algunas comedias humanísticas vemos a jóvenes hijas de familia (virgines) que dan prueba de una iniciativa personal y de una franqueza en temas amorosos que son del todo desconocidas en el teatro clásico.

Quisiera concluir estas líneas ofreciendo el testimonio de dos comedias humanísticas en las que se encuentra este motivo no tradicional de la muchacha enamorada, síntoma claro del nuevo sitial que la mujer fue alcanzando en los últimos siglos del Medioevo, en los albores del Renacimiento. Se trata de Symmachus y de Emporia, de Tito Livio Frulovisi (ca. 1400-post 1456), ambas representadas en Venecia entre los años 1432 y 1435. Son piezas de un latín más plautino que ciceroniano, a ratos peculiar en su estructura y algo ambiguo en su sentido.

De especial importancia nos parece señalar aquí que estas dos comedias no solo no han sido hasta hoy bien editadas críticamente, sino que tampoco, como quedó dicho, han sido traducidas a ninguna lengua moderna. La única edición disponible es la de Previté-Orton, de 1932, insuficiente en varios aspectos. Mi texto latino no reproduce el de esta antigua edición, sino directamente el del único códice en que han llegado hasta nosotros las comedias de Frulovisi: el manuscrito n. ${ }^{\circ} 60$ de St. John's College, Cambridge ${ }^{13}$. Solo en aquellas ocasiones -pocas- en las que, a mi juicio, se presentaban errores de transmisión, he enmendado sus lecturas.

13 Agradezco al St. John's College de Cambridge, que tuvo la gentileza de enviarme una reproducción de este códice. 
Veamos, en primer lugar, el caso de Symmachus. El pasaje que de esta comedia recojo corresponde a los parlamentos iniciales de la escena segunda ${ }^{14}$, donde la joven Piste y la anciana Estigna se hallan enzarzadas en una discusión. La vieja Estigna le reprocha a Piste lo que, a su juicio, son costumbres demasiado frívolas de parte de las muchachas, quienes deberían vivir recluidas en casa y no andar mostrándose provocativamente a los jóvenes. La muchacha, por su parte, reclama para sí el derecho a gozar de su inocente libertad ${ }^{15}$.

PisTe. Virgo sum domi seruata per parentis, ut nostris semper moris fuit. Quod in nobis aer sit, non sine aere uiueremus. Sed dementes isti iuuenes, nos si semel in fenestris uiderint, uelatas quamquam spissis sepibus, ilico se credunt amari.

Stigna. Si domi staretis neque uestri tanta copia fieret, non essemus orbæ nostris liberis.

Piste. Quænam est hæc copia quam dicis? Mali mores urbis, non uirgines in noxa sumus.

Stigna. Quos mores? Nihil nihil nisi Venus estis.
PISTE. Soy una joven custodiada en casa por sus padres, como ha sido siempre nuestra costumbre. Y ya que en nuestros cuerpos hay aire, sin aire no podríamos vivir. Pero basta que esos jóvenes dementes nos vean una sola vez en la ventana, aunque sea veladas por tupidos setos, para que al punto crean que estamos enamoradas de ellos.

Estigna. Si ustedes permanecieran en casa y no se prodigaran tanto, no nos veríamos privadas de nuestros hijos.

PISTE. ¿De qué prodigarse estás hablando? Son las malas costumbres de la ciudad las que tienen la culpa, no nosotras las muchachas.

Estigna. ¿Qué costumbres? Ustedes no son sino lujuriosas Venus.

$14 \quad$ Folio $57 \mathrm{v}$, línea 16 - folio 58r, línea 2.

15 Agradezco la valiosa participación que tuvieron María José Brañes y Javier Beltrán en la traducción de estos fragmentos de Symmachus y Emporia. 
PISTE. Nescio quid Venerem narres. Monachæ sumus. Vestræ fraudes, dolosus animus uester sic facit. Si tales quoque forent omnibus filiæ uirgines qualem me uides, nullæ de quibus essent futuræ deceptiones, nos, quibus insit nihil criminis, magis liberæ uiueremus, et adulescentes, qui nos crebro uiderent, modesti haberentur magis.
PIste. No sé por qué hablas de Venus. Nosotras somos verdaderas monjas. Los responsables son los engaños y el espíritu doloso de ustedes. Si todos tuvieran hijas solteras como yo, de las cuales no habría ningún engaño que temer, nosotras, en quienes no habría ninguna falta que reprochar, viviríamos más libres, y los jóvenes, que nos verían con frecuencia, se comportarían más virtuosamente.

Y veamos, para concluir, el caso de Emporia. El pasaje que aquí recojo de esta comedia -de mayor extensión que el de Symmachus y de especial interés para mi propósito- corresponde a la escena cuarta entera ${ }^{16}$. Allí, Adelfa, la joven enamorada, discute acaloradamente con Parafrón, su padre, sobre sus -según ella- atropellados derechos. La animosa muchacha reconoce paladinamente que está enamorada y se rebela con decisión contra su padre, en quien ve encarnadas las severas normas sociales que la sofocan y le impiden satisfacer su amor.

Paraphron. Qui, malum! Non sunt parentis dicta! Ego pro te meam contriui uitam totam, tantum ut conficerem rei quod honesto uiro locari posses. Hem, quid premii abs te fero? Totam dedecoras familiam nostram teque priuas uiro.

Adelphe. Iam diu, bene si perspicio, priuata sum.

Paraphron. Tace, quam unam iudico mulierum audacissimam.
PARAFrón. ¡Cómo, diablos! ¡Esas no son las palabras de tu padre! Yo he dedicado toda mi vida a buscar tu bien, a reunir la dote necesaria para que pudieras casarte con un hombre honorable. ¡Ah!, ¿y qué recibo de ti a cambio? Tú deshonras a toda nuestra familia y te privas de un esposo.

Adelfa. Mirándolo bien, hace ya un buen tiempo que estoy privada.

PARAFrón. ¡Cállate! Creo que eres la más atrevida de las mujeres. 
AdelPHe. Ahu ehu oi! Rem uideo palam, ut inficiato minime sit opus. Amo, fateor, hunc adulescentulum. Vos æcastor, magnas ut conficiatis dotes, antiquari nos domi grandes sinitis, uel opinor uerius ut ex ipsis dotibus maius uobis conficiatur foenus, et nos lapideas creditis.

Paraphron. Hui fortunam execrandam, ut mea senectute tam impudentem habeam filiam!

Adelphe. Me facit impudentem necessitas. Peccaui, fateor, et id tua culpa, qui me tam grandem domi sedere facias. Monasterio me dicatam puta, quod penuria uiri uenerea siem.

Paraphron. Vtinam ab ineunte ætate uestalem te legissem monacam! Iam non fores impudica.

Adelphe. Sic factum uellem. Vno misello usa sum adulescentulo, strenuo tamen. Illic non defuissent amatores mihi, uel si quisque, non saltem religiosi. Pater, satius nobis foret pauperi cui locari bona ætatula nuptum quam, ubi iam anus sumus factæ, primorum principi.
Adelfa. ¡Ay ay ay! Veo que el asunto ha quedado al descubierto, de modo que no es necesario seguir negándolo. Estoy enamorada de este muchacho, lo confieso. Ustedes (los padres), por Cástor, para amasar grandes dotes, dejan que nosotras, ya adultas, envejezcamos en casa -o más bien, creo, para obtener un mayor rédito de las dotes mismas-, y suponen que nosotras somos de piedra.

PARAFRÓn. ¡Ay, suerte maldita! ¡Que en mi vejez tenga yo una hija tan desvergonzada!

Adelfa. La necesidad me hace desvergonzada. He pecado, lo reconozco, y ello por culpa tuya, puesto que haces que yo permanezca en casa siendo ya adulta. Haz cuenta que estoy confinada en un convento, de modo que soy lasciva por falta de marido.

PARAFRÓN. ¡Ojalá te hubiera escogido para monja desde pequeña! Ahora no serías una desvergonzada.

Adelfa. Me gustaría que hubiera sido así. Con un solo muchacho, modesto pero valiente, he tenido relaciones. Allá, en cambio, no me habrían faltado amantes; y si así hubiera sido, al menos no me habrían faltado clérigos. Padre, para nosotras sería preferible que nos casaran jóvenes con alguien pobre, a que lo hicieran con el mejor de los mejores cuando ya seamos viejas. 
Paraphron. Non dolet istuc mihi minus minus mea quam causa tua. Non decet adulescenti plebeio, pauperi maxime, te uxorem dare. Quod si facerem, hem, aspice quid decoris faceremus. Omnes ilico meretricem te crederent, aut auarorum me parcissimum aut fors insanire. Neque te sacerdotem fieri uelle possum inducere in animum ut credam. Quis me miserior? Te uero domi oportuerit sedere in ætatem ultimam.

Adelphe. Haud inuita manebo, sin ad me poterit huc adulescens proficisci.

PARAPhron. Alia sum usurus diligentia in custodienda tua pudicicia. Mortem oppetet tuus istic amator, si mihi molestus esse perget.

AdELPHE. Pater, non me tam mouet peccatum meum ac uirtus uiri, quam timeo ne funesta sit nostræ familiæ, si cum istoc amatore uobis rei quicquam erit. Lacrumo, misera; in quod me, te fratremque meum conieci malum. Formidolosa mihi non est parum uirtus hominis.

PARAPHRON. Suum est ordinis illius uereri et reuereri meum. Capitis ego perdam illum. Ibo statim ad tris uiros, in neruum illum duci qui iubeant. Ne dubita; non perpetiar ego istuc, metu quod filiam uideam meretricem.

Adelphe. Quin igitur me locas uiro?
PARAFRÓn. Esto no me duele menos por mí que por ti. No corresponde que yo te entregue de esposa a un joven plebeyo, sobre todo pobre. Si lo hiciera, jay!, imagínate qué deshonra sería para nosotros. De inmediato todos creerían que eres una ramera, o que yo soy el más avaro de los avaros, o que me he vuelto loco. Y no puedo convencerme de que quieras hacerte monja. ¿Quién es más desdichado que yo? Será necesario, pues, que te quedes en casa hasta el fin de tus días.

Adelfa. No me quedaré de mala gana, pero siempre que el muchacho pueda venirse para acá.

PARAFrón. Voy a emplear otros medios para custodiar tu reputación. Ese amante tuyo encontrará la muerte si es que continúa fastidiándome.

Adelfa. Padre, más que mi pecado, me preocupa la osadía del joven, que temo que pueda ser funesta para nuestra familia si es que él llega a enfrentarse con ustedes. Lloro, desdichada; a ti y a mi hermano los he puesto en el brete en que me encuentro yo. No resulta poco atemorizante para mí la temeridad del muchacho.

PARAfrón. Al de su clase social le corresponde respetar a su igual y temer al de la mía. Lo voy a aniquilar. Iré de inmediato donde los triunviros para que ordenen que sea llevado a prisión. No tengas dudas; no toleraré que, por temor, tenga yo que verte convertida en una ramera.

Adelfa. Cásame con alguien, entonces. 
Paraphron. Faciam ubi coacta dos sit.

Adelphe. O, infelices mulieres, quas uirorum auaricia nos regat! Alia uestalis legitur, alia domi grandis antiquatur; paucæ uiro bene locantur et tempori. Si quando natæ fuero mater et mihi potestas fuat, potius quam illam uoueam religioni uel internecabo tenellam ipso in partu uel nautarum illam tradidero coco, potius quam usquam committam filia per me quod intret religionem aut sedeat tam grandis domi.

Paraphron. Hui, te nihil quidem impudentius posset haberi!

Adelphe. Tacebo. Æcastor non est miro simile si meretrices sumus. Primum fratres habemus quibus nihil sit ornatius, nihil impudentius. Tum clausæ tenemur annos. Amatores nos colunt. Lingua poscit, corpus petit.

Ignoscendum est, pater; uel etiam si nolis, factum quod est nullo pacto fieri infectum potest. Sin occides me, sic res est ut uides.

PARAPhron. Iam quod te dignum est non facis. Ego quod me dignum sit in te facere conuenero. Procedunt hæc omnia nimio ex ocio. Pol, aliter exercebo te, nos quæ dedecoras. Ibo nunc in forum, meditabor, forsitanue quempiam aduocabo mihi consultorem ex æqualibus meis, quonam pacto iniuriam hanc ulcisci ualeam.
PARAFrón. Lo haré cuando haya reunido la dote.

ADELFA. ¡Oh, infelices mujeres, a quienes nos gobierna la avaricia de los hombres! Una es elegida para monja; otra, ya adulta, envejece en su casa; pocas son casadas bien y a tiempo. Si alguna vez soy madre de una hija y se da la ocasión, o la mataré tiernecita en el parto mismo antes que consagrarla a una religión, o se la entregaré a un cocinero de marineros antes que permitir que por mí entre a una religión o permanezca ya adulta en casa.

PARAFrón. ¡Ay, no es posible imaginarse nada que sea más desvergonzado que tú!

Adelfa. Me callaré. Por Cástor, no es sorprendente que nos convirtamos en rameras. Por una parte, tenemos hermanos que son el colmo del lujo y el descaro, y, por otra, a nosotras nos mantienen encerradas durante años. Los amantes nos expresan su amor.

La lengua pide, el cuerpo busca. Debes perdonarme, padre; y si no quieres hacerlo, ten presente que de ningún modo puede deshacerse lo que ya está hecho. A menos que me mates, la situación es así como la ves.

PARAFrón. No estás haciendo lo que es digno de ti. Ya veré qué es lo que corresponde que haga contigo. Todas estas cosas son resultado del excesivo ocio. Por Pólux, de alguna otra manera te voy a enderezar a ti, que nos deshonras. Ahora iré al foro, reflexionaré, y quizás le pediré a uno de mis camaradas que me aconseje de qué modo puedo vengar esta afrenta. 


\section{CONCLUSIÓN}

La figura de la muchacha enamorada, pues, irrumpe con fuerza en la comedia humanística, que nos muestra un tipo femenino radicalmente nuevo y distinto del de las pasivas meretrices de la comedia antigua. Es cierto que aquí vemos a una mujer todavía sometida, pero es una mujer ya en rebeldía, vigorosa, ávida de goce, con los bríos que muestra en la literatura amorosa del Medioevo, y que desde este momento en adelante enriquecerá la escena con su pujante presencia. Estas muchachas enamoradas de la comedia humanística latina, en efecto, anuncian ya el largo repertorio de enamoradas plenas de vitalidad y humanidad que nos ofrecerá la literatura posterior europea y son testimonio de la emancipación femenina que, a quince siglos de la que tuvo lugar en la antigua Roma, despuntaba nuevamente en el temprano Renacimiento.

\section{BIBLIOGRAFÍA}

MANUSCRITOS:

Ms. n. ${ }^{\circ}$ 60, St. John's College. Cambridge: S. XV.

EDICIONES IMPRESAS:

Femenías, María Luisa. "Mujer y jerarquía natural en Aristóteles”. Hiparquia 1.1 (1988): 8-19.

Frulovisi, Tito Livio. Opera hactenus inedita. Ed. Charles William Previté-Orton. Cambridge: Typis Academiae, 1932.

Gellius, Aulus. Noctes Atticae. Oxford: University Press, 1968.

Iuvenalis. Saturae. Oxford: University Press, 1959.

Lida, María Rosa. "Reseña de Johannes de Vallata, Poliodorus. Comedia humanística desconocida. De José María Casa Homs, Madrid: C. S. I. C, 1953”. Nueva Revista de Filología Hispánica 10 (1956): 415-39.

La originalidad artística de “La Celestina”. 2ª ed. Buenos Aires: Eudeba, 1970.

Livius, Titus. Ab urbe condita. Oxford: University Press, 1965.

Menéndez Pelayo, Marcelino. Orígenes de la novela. 4 vols. Madrid: C.S.I.C., 1943.

Sophocles. Fabulae. Oxford: University Press, 1964.

Stäuble, Antonio. La commedia umanistica del Quattrocento. Firenze: Istituto Nazionale di Studi sul Rinascimento, 1968.

Valerius Maximus. Memorable Doings and Sayings. Massachusetts: Harvard University Press, 2000. 
Valle Lersundi, Fernando del. "Testamento de Fernando de Rojas, autor de La Celestina". Revista de Filología Española 16 (1929): 366-88.

Vergilius. Opera. Oxford: University Press, 1966.

Vidén, Gunhild. Women in Roman Literature: Attitudes of Authors under the Early Empire.

Göteborg: University of Göteborg, Department of Classical Studies, 1993. 